Supporting Information

\title{
Preferential End Functionalization of Au Nanorods through Electrostatic Interactions
}

\author{
P. Pramod, S. T. Shibu Joseph and K. George Thomas* \\ Photosciences and Photonics, Regional Research Laboratory (CSIR), \\ Trivandrum 695 019, India \\ E-mail: georgetk@md3.vsnl.net.in
}

Table of contents

Page No.

1. Instrumental methods.

S2

2. Synthesis of Au nanorods of aspect ratio 2.2, 2.9 and 3.7 S2

3. Synthesis of $1.8 \mathrm{~nm}, 2.7 \mathrm{~nm}, 4.5 \mathrm{~nm}$ and $5.7 \mathrm{~nm}$ Au nanoparticles.

S3

4. HRTEM micrographs of $\mathrm{Au}$ nanorods, $\mathrm{Au}$ nanoparticles and $\mathrm{S5}$ functionalized Au nanorods. 


\section{Instrumental methods and spectroscopic investigations}

The zeta potential values were measured in a zetasizer Nanoseries (M3-PALS) Malvern-ZEN 3600. The electronic absorption spectra were recorded on a Diode Array UV-Visible spectrophotometer (Agilent 8453). For HRTEM studies, samples were prepared by drop casting $100 \mu \mathrm{L}$ of solution from the cuvette on a carbon coated $\mathrm{Cu}$ grid and the solvent was allowed to evaporate and specimens were examined on a $300 \mathrm{KV}$ (JEOL 3010) transmission electron microscope.

\section{Synthesis of Au nanorods}

Gold nanorods were prepared by a photochemical method ${ }^{1}$ and purified by a procedure modified from that reported by Jana. ${ }^{2}$ In the present study; we have used traoctylammonium bromide as the cosurfactant instead of tetradodecylammonium bromide. A growth solution was prepared by dissolving $440 \mathrm{mg}$ of cetyltrimethylammonium bromide and $4.5 \mathrm{mg}$ of tetraoctylammonium bromide in $15 \mathrm{~mL}$ of water in a cylindrical quartz tube (length $15 \mathrm{~cm}$ and diameter $2 \mathrm{~cm}$ ). To this solution, $1.25 \mathrm{~mL}$ of $0.024 \mathrm{M} \mathrm{HAuCl}_{4}$ solution was added along with $325 \mu \mathrm{L}$ of acetone and 225 $\mu \mathrm{L}$ of cyclohexane. It is reported that $\mathrm{AgNO}_{3}$ is essential for synthesizing $\mathrm{Au}$ nanorods and controlling their aspect ratio. To the above solution, $325 \mu \mathrm{L}$ of $0.01 \mathrm{M} \mathrm{AgNO}_{3}$ was added for synthesizing $\mathrm{Au}$ rods of aspect ratio 2.2, $400 \mu \mathrm{L}$ of $0.01 \mathrm{M} \mathrm{AgNO}_{3}$ was added for synthesizing Au rods of aspect ratio 3.0 and $450 \mu \mathrm{L}$ of $0.01 \mathrm{M} \mathrm{AgNO}_{3}$ was added for synthesizing Au rods of aspect ratio 3.7. The quartz tube was closed with a rubber stopper through which a glass rod was inserted $(15 \mathrm{~cm}$ length and $1 \mathrm{~cm}$ diameter). The glass rod helps in reducing the effective thickness of the solution and increases the light absorbance. A photochemical reaction was carried out under $300 \mathrm{~nm}$ irradiation in a Rayonet photochemical reactor for $18 \mathrm{~h}$. Gold nanorods prepared by a photochemical 
method were first purified by centrifugation. The residue obtained after $10 \mathrm{~min}$ of centrifugation $(7000 \mathrm{rpm})$ was dispersed in $2 \mathrm{~mL}$ of $0.7 \mathrm{M}$ CTAB solution and kept undisturbed for $12 \mathrm{~h}$. The supernatant solution was carefully decanted, and the residue was suspended in water. The solution was kept at $5{ }^{\circ} \mathrm{C}$ for $2 \mathrm{~h}$ to remove excess CTAB. Upon cooling, excess CTAB crystallized out which was separated by filtration. The filtrate contains monodisperse Au nanorods that were used directly for various studies.

\section{Synthesis of $1.8 \mathrm{~nm}, 2.7 \mathrm{~nm}$ and $5.7 \mathrm{~nm}$ Au nanoparticles}

$\mathrm{Au}$ nanoparticles were prepared by adopting a place exchange reaction between the octylmercaptyl protected $\mathrm{Au}$ nanoparticles and triethylene glycol thiol. ${ }^{3 \mathrm{a}}$ In a typical synthesis, octylmercaptyl protected $\mathrm{Au}$ nanoparticles $\left(\mathrm{Au}\left(\mathrm{S}-\mathrm{C}_{8} \mathrm{H}_{17}\right)\right)$ of $1.8 \mathrm{~nm}$ was prepared by following the procedure reported by Brust et al. ${ }^{4}$. The product was place exchanged with 5 equivalents of triethylene glycol thiol in dichloromethane by stirring for $12 \mathrm{~h}$ at room temperature. The reaction mixture was evaporated to remove excess of solvent and the residue was then washed with hexane to remove unreacted triethylene glycol thiol and the product was dried. Product was then dissolved in acetonitrile and used for further studies. ${ }^{1} \mathrm{HNMR}$ studies indicate that the surface of place exchanged nanoparticles consist of triethylene glycol as capping agent ( $99 \%)$

\section{Synthesis of $4.5 \mathrm{~nm}$ Au nanoparticles ${ }^{3 b}$}

Triethylene glycol protected Au nanoparticles of $4.5 \mathrm{~nm}$ were prepared by a procedure reported by Huang and coworkers. ${ }^{3 b}$ In a $250 \mathrm{~mL}$ Erlenmeyer flask, methanol $(30 \mathrm{~mL})$ and acetic acid $(5.0 \mathrm{~mL})$ were stirred for $2-5 \mathrm{~min}$. To this solution, $78.0 \mathrm{mg}(0.2$ mmol) of tetrachloroauric acid $\left(\mathrm{HAuCl}_{4} \times 3 \mathrm{H}_{2} \mathrm{O} ; 99.99 \%\right)$ and $13.6 \mathrm{mg}(0.1 \mathrm{mmol})$ of triethylene glycol thiol $\left(\mathrm{EG}_{3} \mathrm{SH}\right)$ were added and stirring was continued for 5 min to gave a clear yellow solution. Subsequently, a solution of sodium borohydride $(75.0 \mathrm{mg}, 2.0$ 
mmol) dissolved in $5.0 \mathrm{~mL}$ of distilled water was added drop wise to the above solution with rapid stirring. On addition of the first drop of $\mathrm{NaBH}_{4}$, the $\mathrm{HAuCl}_{4}$ solution immediately turned to dark brown and rapid stirring was continued for $2 \mathrm{~h}$. The reaction mixture was transferred into a $10 \mathrm{~mL}$ plastic centrifuging tube and centrifuged at 2500 rpm for $30 \mathrm{~s}$ to remove any large particles present. The supernatant liquid was then filtered through a filter paper, concentrated under vacuum to remove methanol and acetic acid, washed several times with ether to remove the unreacted thiol. The product was dissolved in dichloromethane and extracted with water to remove excess sodium borohydride. The organic layer was dried over anhydrous $\mathrm{Na}_{2} \mathrm{SO}_{4}$. After removing the solvent, the product was dried and dissolved in acetonitrile $(10 \mathrm{~mL})$ for further studies.

\section{References}

(1) Kim, F.; Song, J. H.; Yang, P. D. J. Am. Chem. Soc. 2002, 124, 14316.

(2) (a) Jana, N. R.; Gearheart, L.; Murphy, C. J. J. Phys. Chem. B 2001, 105, 4065. (b)Busbee, B. D.; Obare, S. O.; Murphy, C. J. Adv. Mater. 2003, 15, 414. (c) Jana, N. R. Chem. Commun. 2003, 1950.

(3) (a) Foos, E. E.; Snow, A. W.; Twigg, M. E.; Ancona, M. G. Chem. Mater. 2002, 14, 2401. (b) Zheng, M.; Li, Z.; Huang, X. Langmuir 2004, 20, 4226.

(4) Brust, M.; Walker, M.; Bethell, D.; Schffrin, D. J.; Whyman, R. J. Chem. Soc., Chem. Commun. 1994, 801. 


\section{HRTEM micrographs of Au nanorods and Au nanoparticles}
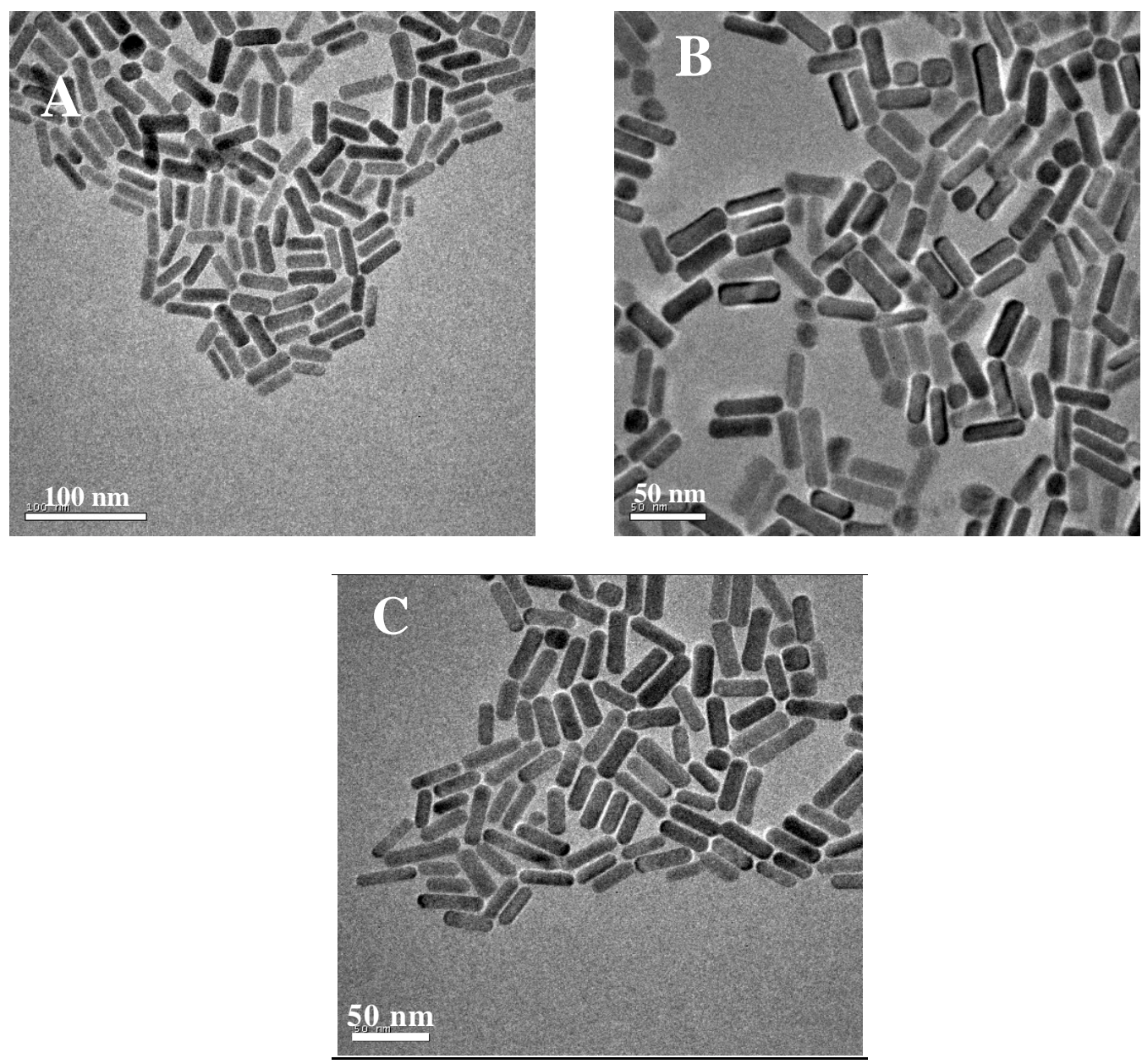

Figure S1. HRTEM images of gold nanorods of varying aspect ratios: (A) 3.7. (B) 3.0 and $(\mathrm{C}) 2.2$.

\section{Rod dimensions}

The average length and aspect ratio of Au nanorods were estimated by analyzing 100 nanorods and the results indicate excellent monodispersity. The average dimensions and aspect ratio of the nanorods are listed below

\subsection{Aspect ratio Au nanorods}

Length $=28 \mathrm{~nm}$

Diameter $=12.5 \mathrm{~nm}$

\section{0 aspect ratio Au nanorods}

Length $=36 \mathrm{~nm}$

Diameter $=12 \mathrm{~nm}$

\section{7 aspect ratio Au nanorods}

Length $=45 \mathrm{~nm}$

Diameter $=12 \mathrm{~nm}$ 


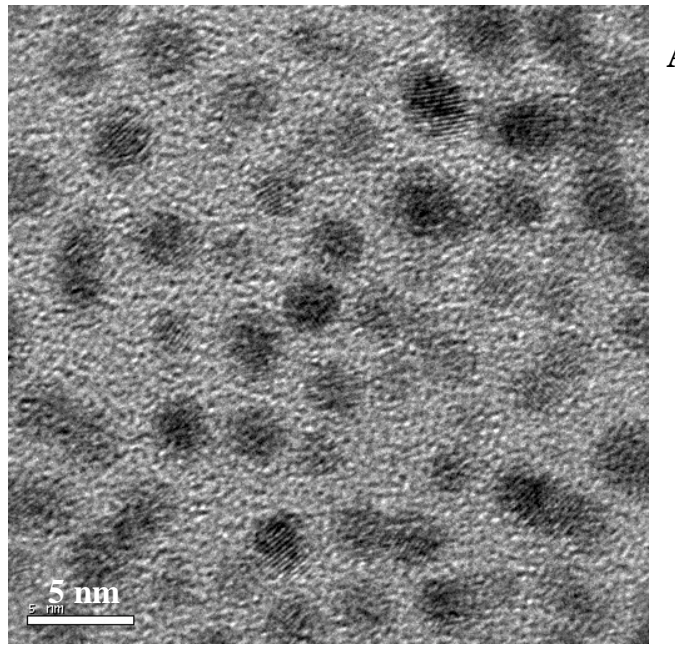

A
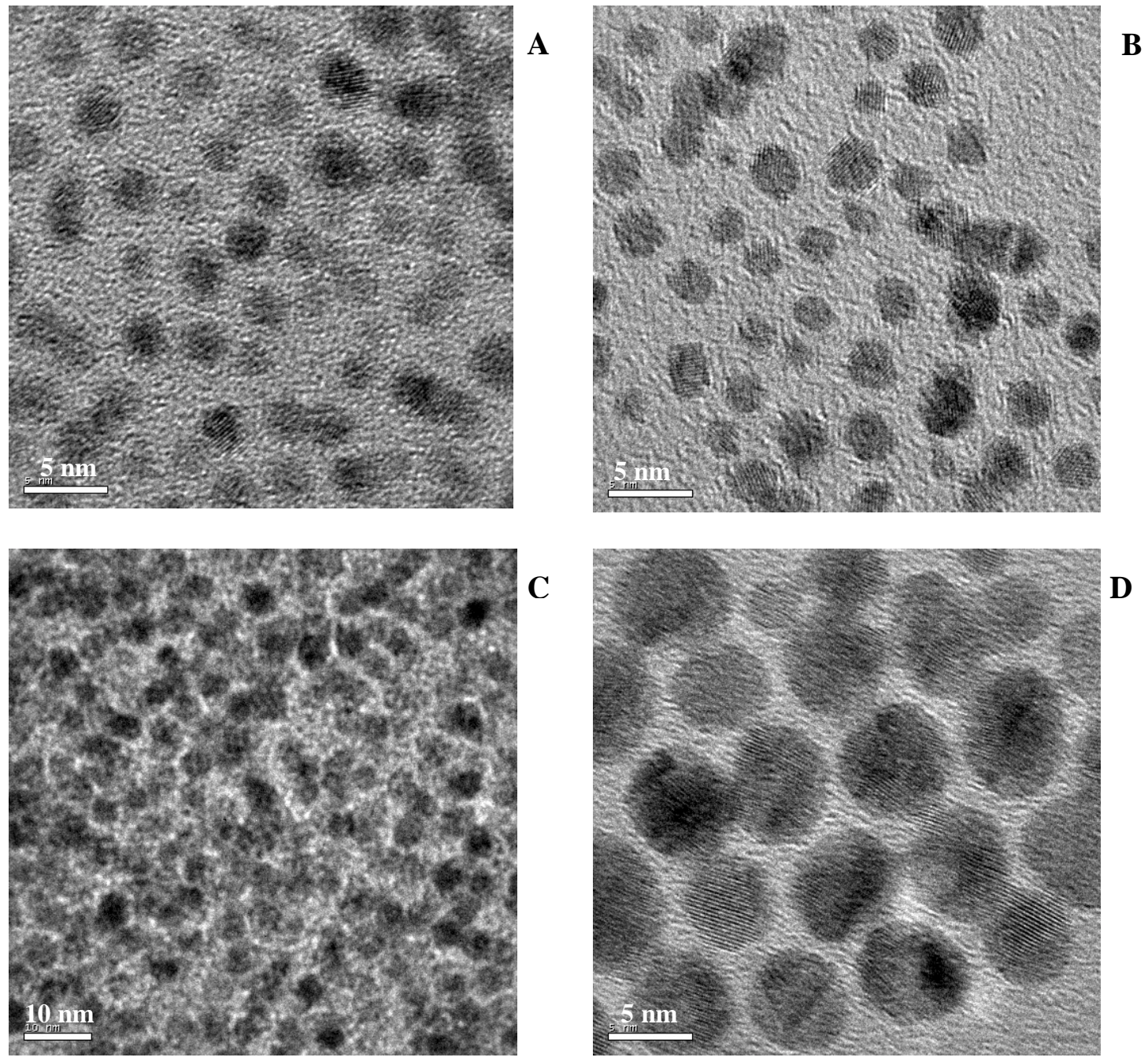

Figure S2. HRTEM images of (A) $1.8 \mathrm{~nm}$, (B) $2.7 \mathrm{~nm}$, (C) $4.5 \mathrm{~nm}$ and (D) $5.7 \mathrm{~nm}$ Au nanoparticles. 


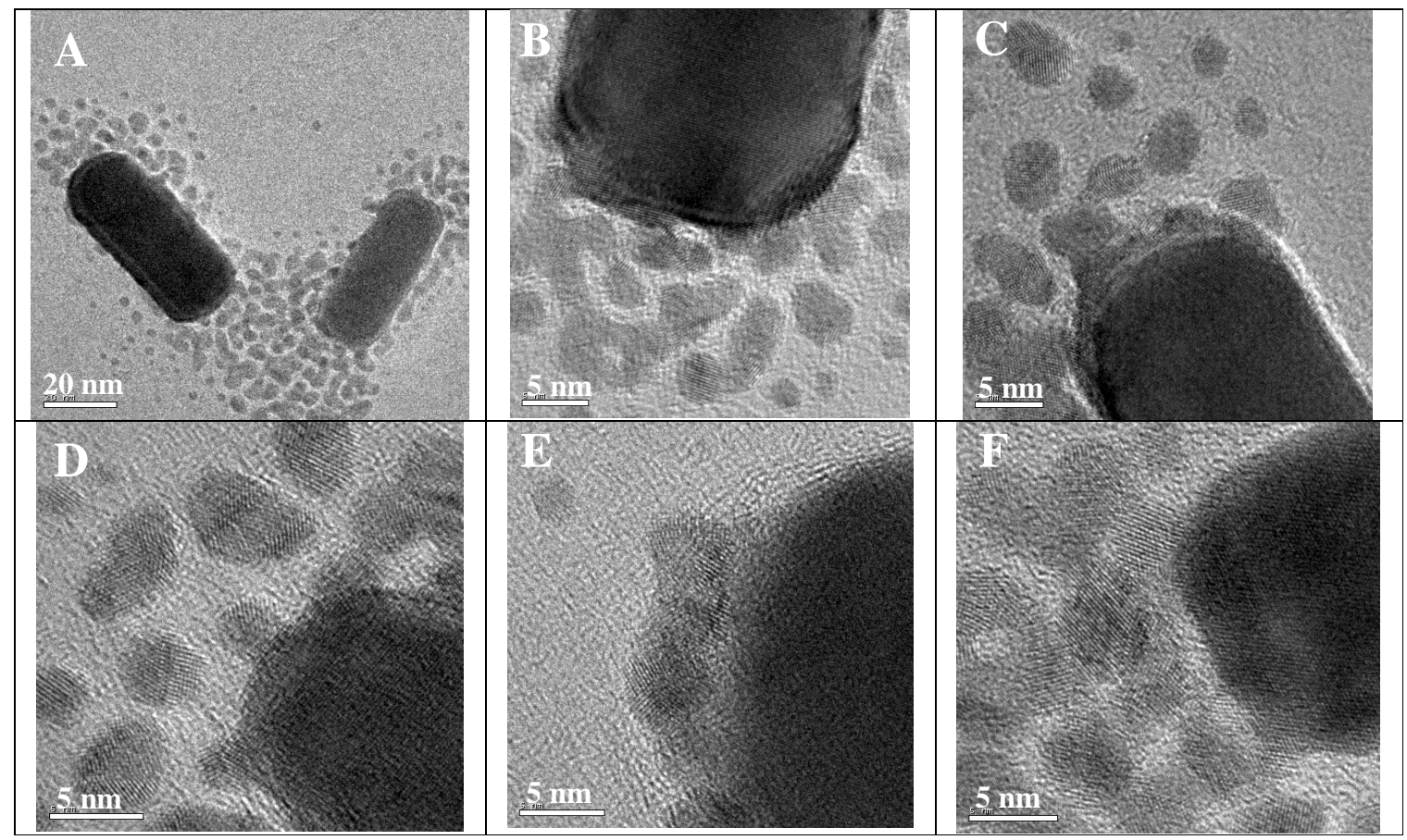

Figure S3. (A)-(F) HRTEM images of $\mathrm{Au}$ nanorods on the addition of $\mathrm{Au}$ nanoparticles.
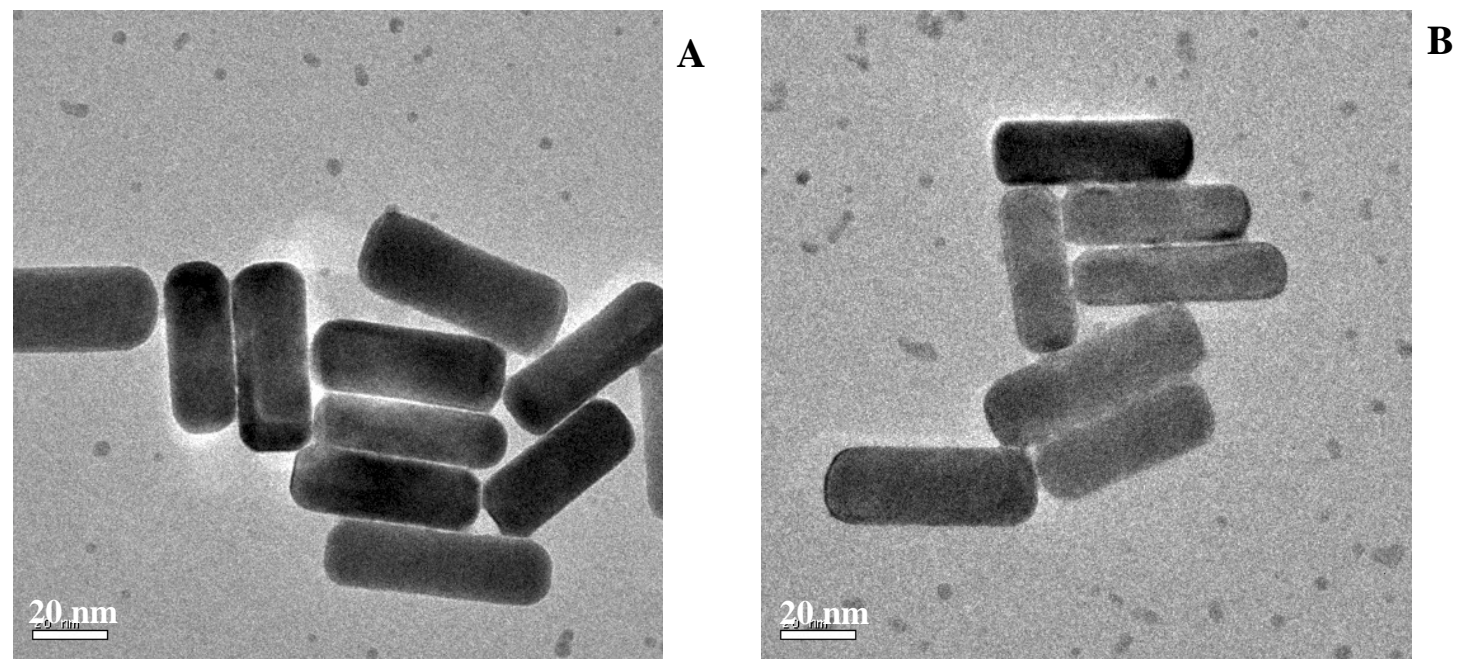

Figure S4. (A)-(B) HRTEM images of 3.7 aspect ratio Au nanorods on the addition of $5.7 \mathrm{~nm}$ Au nanoparticles. 